\title{
Size-dependent ecotoxicity of barium titanate particles: the case of Chlorella vulgaris green algae
}

\author{
Hudson C. Polonini • Humberto M. Brandão • Nádia R. B. Raposo • \\ Marcos Antônio F. Brandão • Ludovic Mouton · Alain Couté • \\ Claude Yéprémian • Yann Sivry • Roberta Brayner
}

Accepted: 23 February 2015/Published online: 13 March 2015

(C) Springer Science+Business Media New York 2015

\begin{abstract}
Studies have been demonstrating that smaller particles can lead to unexpected and diverse ecotoxicological effects when compared to those caused by the bulk material. In this study, the chemical composition, size and shape, state of dispersion, and surface's charge, area and physicochemistry of micro (BT MP) and nano barium titanate (BT NP) were determined. Green algae Chlorella vulgaris grown in Bold's Basal (BB) medium or Seine River water (SRW) was used as biological indicator to assess their aquatic toxicology. Responses such as growth inhibition, cell viability, superoxide dismutase (SOD) activity, adenosine-5-triphosphate (ATP) content and photosynthetic activity were evaluated. Tetragonal BT $\left(\sim 170 \mathrm{~nm}, 3.24 \mathrm{~m}^{2} \mathrm{~g}^{-1}\right.$ surface area) and cubic BT $\left(\sim 60 \mathrm{~nm}, 16.60 \mathrm{~m}^{2} \mathrm{~g}^{-1}\right)$ particles were negative, poorly dispersed, and readily aggregated. BT has a
\end{abstract}

Electronic supplementary material The online version of this article (doi:10.1007/s10646-015-1436-6) contains supplementary material, which is available to authorized users.

H. C. Polonini · N. R. B. Raposo · M. A. F. Brandão

Núcleo de Pesquisa e Inovação em Ciências da Saúde

(NUPICS), Universidade Federal de Juiz de Fora, Juiz de Fora, Brazil

H. M. Brandão

Empresa Brasileira de Pesquisa Agropecuária (Embrapa Gado de Leite), Juiz de Fora, Brazil

H. M. Brandão

CiPharma, Escola de Farmácia, Universidade Federal de Ouro Preto, Campus Morro do Cruzeiro, Ouro Preto, MG 35400-000, Brazil

L. Mouton · R. Brayner $(\bowtie)$

Interfaces, Traitements, Organisation et Dynamique des

Systèmes (ITODYS), Université Paris Diderot, Sorbonne Paris statistically significant effect on $C$. vulgaris growth since the lower concentration tested (1 ppm), what seems to be mediated by induced oxidative stress caused by the particles (increased SOD activity and decreased photosynthetic efficiency and intracellular ATP content). The toxic effects were more pronounced when the algae was grown in SRW. Size does not seem to be an issue influencing the toxicity in BT particles toxicity since micro- and nano-particles produced significant effects on algae growth.

Keywords Barium titanate - Seine river water . Ecotoxicology $\cdot$ Characterization $\cdot$ Nanotechnology

\section{Introduction}

The current trend in engineering and using nanoscale materials in commercial products is a recent but wellknown and documented phenomenon (Brayner et al.

Cité, UMR 7086, CNRS, 15 rue Jean-Antoine de Baï,

75205 Paris, France

e-mail: roberta.brayner@univ-paris-diderot.fr

A. Couté · C. Yéprémian

Muséum National d'Histoire Naturelle, Paris, France

Y. Sivry

Institute de Physique du Globe de Paris (IPGP), Université Paris

Diderot, Sorbonne Paris Cité, Paris, France 
2006, 2010; Pang et al. 2012). However, the increase in their use was not preceded by any regulatory framework, especially regarding the potential risks they can pose to ecosystems (Tiede et al. 2009; Cullen et al. 2011), and questions have been raised as to whether these smaller particles need different regulations from the ones applied to microscopic forms of the same substances (Rogers et al. 2010).

Indeed, until now the studies have been demonstrating that smaller particles can lead to unexpected and diverse ecotoxicological effects from the ones caused by the bulk material, even when the latter is relatively inert (Handy et al. 2008; Nowack 2009). This is because the size and the shape, and consequently the surface area, influence the interactions and the uptake/distribution of the particles within the organisms (Brayner et al. 2010). Within this context, nanoecotoxicology has been gradually progressing as an emerging multidisciplinary field of research, improving our knowledge and our relations with these new materials.

Among the materials that have been studied in the hopes of finding new applications when in small size, we can name the ceramic materials based on perovskite-like oxides, out of which barium titanate $\left(\mathrm{BT}, \mathrm{BaTiO}_{3}\right)$ is one the most important and employable materials in industry. Despite the significant momentum it has been gaining in the electroceramics/nanotechnology field, only a few investigations regarding its biological applications can be found in the literature. In fact, until 2010 there was no previous report concerning barium titanate bio-applications, when Ciofani et al. (2010a) published their first work towards its utilization as a nanocarrier for proteins. After that, another applications began to emerge, which included its use as an uptake enhancer of low molecular weight drugs such as doxorubicin (Ciofani et al. 2010b); as biomarker, through the bioconjugation of its nanocrystals with immunoglobulin $\mathrm{G}$ antibodies for imaging probes (Hsieh et al. 2010); and in the design of bone graft material (Ball et al. 2014). However, studies on its impact on the environment are lacking.

In this study, we used the green algae Chlorella vulgaris grown both in artificial and natural culture medium (Bold's Basal, BB, or Seine River water, SRW, respectively) as a model organism to assess the aquatic toxicology of BT with two different particle sizes for the first time. Given this, our primary objectives were: (i) to assess the BT toxicity and its mechanisms into the aquatic environment, using a primary producer, photosynthetic microorganism, as biological indicator; (ii) to compare the BT behavior and toxic profile in synthetic and natural culture media; and (iii) to address whether size is an issue in BT particles toxicity.

\section{Materials and methods}

The subjects of the study: BT particles and Chlorella vulgaris model-organism

\section{BT characterization}

Two different lots of BT powders were obtained from Sigma-Aldrich: BT-MP (lot MKBD3182V, $<2 \mu \mathrm{m}$ ) and BT-NP (lot MKBF7837V, <100 nm).

The X-ray diffraction (XRD) patterns of the powders were recorded with a X'pert Pro diffractometer (PANalytical), equipped with a multichannel $\mathrm{X}$ 'celerator detector, and using the $\mathrm{Co} \mathrm{K} \alpha$ radiation $(=1.790307 \AA)$, in the $2 \theta$ range $5^{\circ}-120^{\circ}$, with a scan step of $0.05^{\circ}$ for $5 \mathrm{~s}$. The sample holder used was a Si monocrystal.

Morphological observation of powders by scanning electron microscopy (SEM) was obtained by using a Zeiss Supra 40 microscope equipped with an in-lens detector. Low excitation voltage $(2.5 \mathrm{kV})$ and a small working distance (3 mm) were used. Transmission electron microscopy (TEM) images were obtained in a JEOL 100CX-II microscope operating with an accelerating voltage of $100 \mathrm{kV}$.

The specific surface area $(\mathrm{Sg})$ and pore size were measured by the collection of nitrogen $\left(\mathrm{N}_{2}\right)$ adsorption-desorption isotherms on a Gemini V 2380 system (Mic America, Inc.) at $77 \mathrm{~K}$ after the sample had been dried at $160{ }^{\circ} \mathrm{C}$ for $1 \mathrm{~h}$. The Brunauer-Emmett-Teller (BET) surface area was calculated from the linear part of the BET plot. The pore size distribution was obtained from a QUANTACHROME-Autoscan 33 mercury porosimeter.

The hydrodynamic size and the surface charge/interparticle forces (zeta potential, $\zeta$ ) of the dispersions of BT powders $\left(100 \mu \mathrm{g} \mathrm{mL}^{-1}\right.$, or $4.28 \times 10^{-7} \mathrm{M}$, in BB medium and SRW) were characterized using a Sizer Nano ZS (Malvern Instruments Inc.). Effects of $\mathrm{pH}$ variation in the media $\left(3,5,7,9,12\right.$, adjusted with $\mathrm{HNO}_{3}$ or $\mathrm{NaOH}$ in different molarities) were evaluated, as well as the degree of aggregation as a function of time $(0,24,48,72$ and $96 \mathrm{~h})$. The dispersions were sonicated $(200 \mathrm{~W}, 5 \mathrm{~min})$ daily before analysis in order to disperse agglomerates so that it could be inferred that increased hydrodynamic sizes were due to aggregation. Response surfaces were built-up in order to evaluate the roles each factor played at the aggregation state or the surface charge of the BT dispersions. A $5^{2}$ factorial experimental design (two factors, time and $\mathrm{pH}$, with 5 levels of variations each) were performed accordingly to Montgomery (2012) and Polonini et al. (2011) (see Supplementary Material), which provide the theoretical background for the graphical representation used. The factors and their levels (codified levels in parenthesis, and real ones outside them) were $\mathrm{X}_{1}$ : time 
[(-1) $0 \mathrm{~h},(-0.5) 24 \mathrm{~h},(0) 48 \mathrm{~h},(0.5) 72 \mathrm{~h},(1) 96 \mathrm{~h}]$ and $\mathrm{X}_{2}: \mathrm{pH}[(-0.88) 3,(-0.44) 5$, (0) 7, (0,44) 9, (0.88) 12].

The degree of dissolution of the BT powders as a function of time $(1,2,4,8,24,48,72$ and $96 \mathrm{~h})$ within the media (BB medium and SRW) was evaluated by following a protocol proposed by Sivry et al. (2014). From a stock solution $\left(100 \mu \mathrm{g} \mathrm{mL}^{-1}\right)$ prepared at time 0 , aliquots $(3.5 \mathrm{~mL})$ were withdrawn at the specified time intervals and ultra-filtered using $3 \mathrm{kDa}$ filters (Microsep Advance Centrifugal Device, Pall Corporation), placed in a centrifuge (EBA 8, Hettich) for $1 \mathrm{~h}$, and then added with $50 \mu \mathrm{L}$ of saturated $\mathrm{HNO}_{3}$ (with no trace of $\mathrm{Ba}^{2+}$ ). All solutions were immediately frozen until elemental analysis $\left(\mathrm{Ba}^{2+}\right)$ was performed by inductively coupled plasma optical emission spectrometry (ICP-OES) (iCAP 6200, Thermo Scientific). Detection limit was set as $1.0 \mathrm{ppb}$. The remaining aqueous dispersion $(72 \mathrm{~mL})$ was centrifuged at $20,000 \times g$ (Sorvall Lynx 6000, Thermo Scientific) and the media was completely evaporated in an oven at $50{ }^{\circ} \mathrm{C}$. The dry residues were then analyzed by XRD and X-ray photoelectron spectroscopy (XPS) (Thermo VG Escalab 250, using $\mathrm{Al} \mathrm{K} \alpha$ of $1486.6 \mathrm{eV}, 15 \mathrm{kV}, 150 \mathrm{~W}$ ) for evaluation of the chemical/surface changes that might possibly have occurred.

All reagents were analytical grade, and ultrapure water (18.2 $\mathrm{M} \Omega \mathrm{cm}$ resistivity at $25{ }^{\circ} \mathrm{C}$ and $<10 \mathrm{ppb}$ total organic carbon) was obtained with an Elga Pure-Lab UV.

\section{C. vulgaris cell culture}

Chlorella vulgaris, a planktonic eukaryotic single-cell green algae, was grown in $275 \mathrm{~mL}\left(=75 \mathrm{~cm}^{2}\right)$ erlenmeyer flasks with air-permeable stoppers, in (i) sterile BB medium (Supplementary Table S1) with $\mathrm{pH}$ adjusted to 7.0 using $1 \mathrm{M} \mathrm{NaOH}$ solution, or (ii) SRW (measured pH 8.01) (Supplementary Table S2). All cultures were kept at a controlled temperature of $20.0 \pm 0.5^{\circ} \mathrm{C}$ and a daily cycle of $16 \mathrm{~h}$ of luminosity $\left(50-80 \mu \mathrm{mol} \mathrm{m}{ }^{-2} \mathrm{~s}^{-1}\right.$ photosynthetic photon flux, PPF), under ambient $\mathrm{CO}_{2}$ conditions.

SRW, representative of a highly anthropized watershed, was collected near the Université Paris Diderot, France (GPS: $48.831039^{\circ} \mathrm{N}, 2.381709^{\circ} \mathrm{E}$ ). The sample was immediately filtered after collection through a $0.22 \mu \mathrm{m}$ acetate membrane (Millipore) under vacuum to remove contaminants and microorganisms and stored in precleaned, acid-washed polyethylene bottles, at $4{ }^{\circ} \mathrm{C}$ until analysis.

\section{Toxicological assessment}

Stock suspensions containing $1000 \mu \mathrm{g} \mathrm{mL}^{-1}$ by weight of BT powders were obtained by sonicating aliquots of $10 \mathrm{mg}$ of BT MP or BT NP in $10 \mathrm{~mL}$ of Seine water or BB medium for $10 \mathrm{~min}$ at $200 \mathrm{~W}$ (VWR, USA). The sonication was used to break micrometric aggregates and stabilize the suspensions. Aliquots of these suspensions were then added to the batch cultures (exponential growth algae, prepared 3 days before the start of the test at a concentration of $5.0 \times 10^{5}$ cells $\mathrm{mL}^{-1}$ ) to obtain the final BT powder concentrations of $1,25,50,75$ and $100 \mu \mathrm{g} \mathrm{mL}^{-1}$ (or $4.28 \times 10^{-6}, 1.07 \times 10^{-4}, 2.14 \times 10^{-4}, 3.22 \times 10^{-4}$, and $4.28 \times 10^{-4} \mathrm{M}$, respectively). Therefore, this study uses higher concentrations than what is forecasted for contamination in natural water, aiming to assess the acute toxicity of the materials. Yet, the experiment was also conducted with $\mathrm{Ba}^{2+}$ at $1.5 \mu \mathrm{g} \mathrm{mL}^{-1}\left(1.09 \times 10^{-5} \mathrm{M}\right)$ because of the maximum degree of dissolved $\mathrm{Ba}^{2+}$ as a function of time, which did not exceed $1.5 \%$ at the final of the experiment (out of $100 \mu \mathrm{g} \mathrm{mL}^{-1}$ ).

The toxic response was evaluated as cell counting at 24 , 48, 72 and $96 \mathrm{~h}$ after the addition of BT powders, as a function of the exposure concentration in comparison with the average growth of replicate, unexposed control cultures. Cell counting was performed with bright field microscopy using the Cellometer Auto X4 (Nexcelom, USA), which simultaneously calculates the percentage of cell viability (live/dead test, conducted with the trypan blue dye, which selectively colors dead cells blue) (Strober, 2001).

Assessment of the factors linked to the toxicity

\section{Microscopic observation}

The interaction between the test organisms and the treatments $\left(100 \mu \mathrm{g} \mathrm{mL}^{-1}\right.$, after $72 \mathrm{~h}$ of exposure) were observed using SEM and TEM. For SEM, control and treatments were fixed with a mixture containing $2.5 \%$ of glutaraldehyde and $1.0 \%$ of picric acid in phosphate Sörengen Buffer (0.1 M, pH 7.4). Dehydration was then achieved in a series of ethanol baths (from 50 to100\%). The samples were dried with a BAL-TEC CDP 030 supercritical point dryer after ethanol baths. The images were obtained in a Zeiss Supra 40 microscope equipped with an in-lens detector. Low excitation voltage $(2.5 \mathrm{kV})$ and a small working distance $(3 \mathrm{~mm})$ were used, so that the charging effects were minimal to the point that the metallization of powders was not necessary, and then true features were not masked. For TEM, control and treatments were fixed with a mixture containing $2.5 \%$ of glutaraldehyde and $1.0 \%$ of picric acid in phosphate Sörengen Buffer (0.1 M, pH 7.4). Post-fixation using osmium tetroxide $\left(\mathrm{OsO}_{4}\right)$ was conducted and the dehydration was achieved in a series of ethanol baths (from 50 to $100 \%$ ). The samples were processed for flat embedding in a Spurr resin, and then ultrathin sections were made using a 
Reicherd-Young Ultracut microtome (Leica). Sections were contrasted with a $4 \%$ aqueous uranyl acetate solution and Reynold's lead citrate before visualization, which was performed in a Tecnai 12 operating at $80 \mathrm{kV}$ equipped with a $1 \mathrm{~K} \times 1 \mathrm{~K}$ Keen Viewcamera.

\section{Effect of particles on aggregation and surface charge of algae}

The hydrodynamic size and the zeta potential of the algae cultures with added BT MP or BT NP in BB medium or SWR $\left(100 \mu \mathrm{g} \mathrm{mL}^{-1}\right.$, at $0,24,48,72$ and $96 \mathrm{~h}$ of exposure) were characterized using a ZetaSizer Nano ZS (Malvern Instruments Inc.).

\section{Effect of particles on algae oxidative stress}

Superoxide dismutase (SOD), which catalyzes the dismutation of the superoxide anion $\left(\mathrm{O}_{2}-\right)$ into hydrogen peroxide and molecular oxygen, was quantified in the controls and treatments $\left(1,50\right.$ and $100 \mu \mathrm{g} \mathrm{mL}^{-1}$, at 24, 48, 72 and $96 \mathrm{~h}$ of exposure) using a SOD Assay Kit-WST 19160 (Sigma-Aldrich, Germany). This allows very convenient SOD assaying by utilizing Dojindo's highly water-soluble tetrazolium salt, WST-1 (2-(4-Iodophenyl)- 3-(4-nitrophenyl)-5-(2,4-disulfophenyl)-2H-tetrazolium, monosodium salt) that produces a water-soluble formazan dye upon reduction with a superoxide anion. The rate of the reduction with $\mathrm{O}_{2}$ is linearly related to the xanthine oxidase (XO) activity, and it is inhibited by SOD. Therefore, the $\mathrm{IC}_{50}(50 \%$ inhibition activity of SOD or SOD-like materials) can be colorimetrically determined. The controls and treatments were incubated at $37^{\circ} \mathrm{C}$ for $20 \mathrm{~min}$, and then read at $450 \mathrm{~nm}$ using an Envision Multilabel Plate Reader (Perkin-Elmer, USA).

\section{Effect of particles on algae photosynthetic activity}

The photosynthetic activity of the controls and treatments $\left(1,50\right.$ and $100 \mu \mathrm{g} \mathrm{mL}^{-1}$, at $24,48,72$ and $96 \mathrm{~h}$ of exposure) were determined through the pulsed amplitude modulation (PAM) method, using a Handy PEA (Hansatech, UK) fluorometer. This method uses the saturation pulse principle, in which a sample is subjected to a short pulse of light that saturates the photosystem II (PSII) reaction centers of the active chlorophyll molecules. This process suppresses photochemical quenching, which might otherwise reduce the maximum fluorescence yield. A ratio of variable over maximal fluorescence $\left(F_{v} / F_{m}\right)$ can then be calculated, which approximates the potential quantum yield of PSII.

\section{Effect of particles on algae mitochondria}

Intracellular levels of adenosine-5-triphosphate (ATP) in controls and treatments $\left(1,50\right.$ and $100 \mu \mathrm{g} \mathrm{mL}^{-1}$, at 24, 48, 72 and $96 \mathrm{~h}$ of exposure) were quantified using an ATP Bioluminescent Assay (Sigma-Aldrich) following the standard protocol provided by the vendor of the kit. Briefly, algae cells were mechanically lysed in a vortex using glass beads followed by centrifugation $(15 \mathrm{~min}$ at $2000 \times \mathrm{g})$, in order to obtain the free ATP at the supernatant. Next, the resulting solution was mixed with $50 \mu \mathrm{L}$ of the Luciferase Reagent. A plate reader was used to quantitative determinate the ATP, and the relative luminescent units were detected with an Envision Multilabel Plate Reader equipped with a luminescent optical filter. The ATP concentrations of the samples were calculated using an ATP standard.

Statistical analysis

Statistical analyses were performed using SPSS v.14.0. For comparisons among control and treatments, two-way analysis of variance (ANOVA) test followed by Tukeys' post hoc test was conducted for the variables that meet the criteria of normality (Shapiro-Wilk test, $p>0.05$ ), homoscedasticity (variance homogeneity, Levene test, $p>0.05$ ) and independence (Durbin Watson test, $p \sim 2.0$ ). For the variables that did violate the assumptions for ANOVA valitidy, a non-parametric Kruskal-Wallys test was conducted. Differences between groups were considered statistically significant when $p \leq 0.05$ and marginally significant when $0.05<p \leq 0.1$.

\section{Results and discussion}

\section{BT characterization}

The complete characterization of the powders can be found in Supplementary Material. They were identified by XRD as tetragonal $\mathrm{BaTiO}_{3}$ (BT MP) and cubic $\mathrm{BaTiO}_{3}$ (BT NP), with average crystallite sizes of $172.0 \pm 102.4 \AA$ (with $0.19 \pm 0.06 \%$ of micro strain) and $60.0 \pm 16.7 \AA$ $(0.10 \pm 0.05 \%)$, respectively. Using SEM and TEM (Fig. 1), the diameter of the particles could be estimated as $170 \mathrm{~nm}$ (BT MP) and $60 \mathrm{~nm}$ (BT NP) (monocrystallines), and the BT MP presented some degree of polydispersion. The BET surface area was calculated as $3.24 \mathrm{~m}^{2} \mathrm{~g}^{-1}$ for BT MP and $16.60 \mathrm{~m}^{2} \mathrm{~g}^{-1}$ for BT NP, the total pore volumes were 0.006 and $0.07 \mathrm{~cm}^{3} \mathrm{~g}^{-1}$, respectively, and the mean pore diameters were 7.34 and $17.46 \mathrm{~nm}$, respectively.

Since BT has a perovskite structure, it is shown to be thermodynamically unstable, also presenting some degree of reactivity in aqueous environment (Lee 1998), what is 

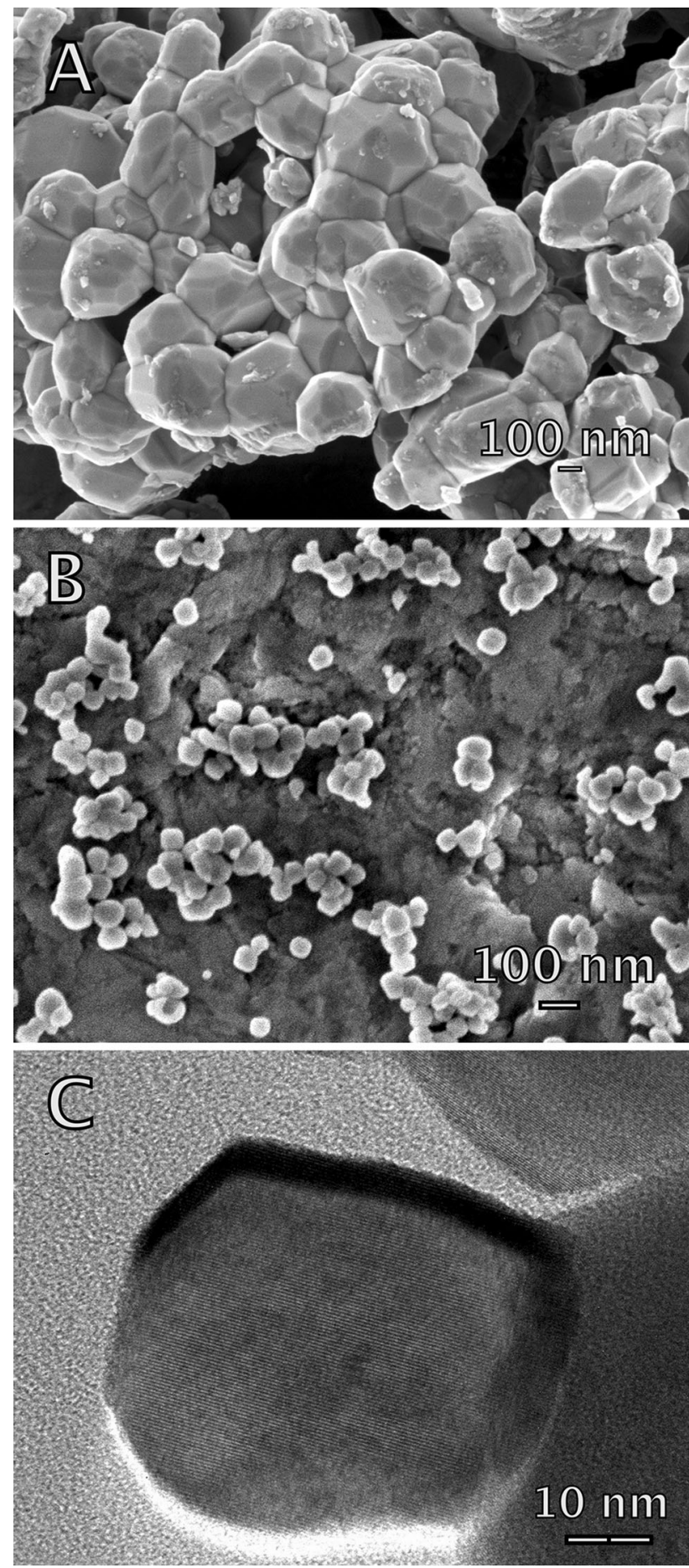

Fig. 1 a BT MP SEM, b BT NP SEM, and c BT NP TEM

evidenced by the DLS measurements performed (Supplementary Fig. S3). Although the particles did not seem to follow a trend for its surface charge behavior, zeta potential results showed that in a general manner they are both negatively charged, disregarding the $\mathrm{pH}$ of the medium or the time they were in suspension. BT MP demonstrated having a higher charge than BT NP in modulus. This can account for a higher reactivity for BT NP, although none of the materials showed values high enough to ensure colloidal stability, which must be at minimum $25 \mathrm{mV}$ (Planchon et al. 2013). This instability may lead to the formation of aggregates of particles. With respect to the media, SRW showed an increased instability for the particles. As surface charge affects the uptake and the translocation of the particles by live organisms (Hoshino et al. 2004), it can be expected that the particles will show distinct effects on the algae, either because of their very nature or due to their different behavior in each medium.

The gradual rise in zeta potential with decreased $\mathrm{pH}$ values can be understood by the fact that the acidic media would leach out the $\mathrm{Ba}^{2+}$ from the BT surface. This leaching out occurrence can interfere in the toxicological assessments, therefore being assessed by means of a dissolution experiment of BT particles into the media at the $\mathrm{pH}$ that the experiments would be conducted (7.0 for BB and 8.01 for SRW) (Supplementary Fig. S4a). BT NP released more $\mathrm{Ba}^{2+}$ in the media than BT MP-1,132 ppb after $96 \mathrm{~h}$ in BB medium, 6.5 times more than BT MP in the same medium, and 1,368 ppb in SRW after the same period, 3.4 times greater than BT MP. The higher porosity of BT NP can have played a role in this greater $\mathrm{Ba}^{2+}$ leaching out process from the surface. As for the media, SRW had a more pronounced effect in the phenomenon than BB medium, once it dissolved BT MP 2.9 times more than the BB medium, and BT NP 1.2 times greater. Thus, such differences can be attributed to the compositional differences between the two media rather than to their $\mathrm{pH}$, once SRW has a slightly higher $\mathrm{pH}$ than $\mathrm{BB}$ medium. Yet, the dissolution rates of the powders in BB medium or SRW were not greater than $1.5 \%$. This is the reason why this was the concentration of free $\mathrm{Ba}^{2+}$ ions chosen $\left(1.5 \mu \mathrm{g} \mathrm{mL}^{-1}\right.$, or $\left.7.28 \times 10^{-6} \mathrm{M}\right)$ to perform the toxicological assessment.

After the 96-h experiments, the XRD patterns of the remaining powders were assessed (Supplementary Fig. S4b), and no significant difference was observed, for both BB medium and SRW. XPS analyses of the residues surfaces were also performed, and the results can be seen in Supplementary Table S3. The $\mathrm{Ba} / \mathrm{Ti} / \mathrm{O}$ ratio is in good agreement with the low solubility verified by ICP-OES. Carbon (C) is a common impurity in ultrahigh vacuum (UHV), and the signals around $285 \mathrm{eV}$ (hydrocarbon) are ordinarily used as internal standard to reference other elements when charging occurs (López et al. 1999). However, its presence in more than one state is an indicative of the formation of $\mathrm{BaCO}_{3}$ (also observed by Ba binding energy at $\sim 780 \mathrm{eV}$ ). The deconvolution of the $\mathrm{C} 1 s$ peak gave a peak of carbonate in a $\mathrm{BaCO}_{3}$ surface, at $288-289 \mathrm{eV} . \mathrm{BaCO}_{3}$ may derived from the tendency for $\mathrm{CO}_{2}$ to adsorb on perovskite surfaces, due to dipole-dipole interaction between the ferroelectric $\mathrm{BaTiO}_{3}$ crystal and the polar $\mathrm{CO}_{2}$ molecule 
(López et al. 1999). As this component is absent in the traces, one can expect that the carbonate may be formed as a discrete second phase $(\sim 2 \%)$ rather than as a surface film, which justifies the fact that this was not detected by XRD.

Another physicochemical parameter of the particles that is directly related to their interaction with living systems is their size, as it is related to the degree of absorption, distribution, metabolism and excretion by live organisms (Jiang et al. 2009; Choi et al. 2007). In the same manner, surface charge affects the up-take and translocation of the particles by these organisms (Hoshino et al. 2004). The hydrodynamic size of the particles was evaluated as a function of $\mathrm{pH}$ and time (Supplementary Fig. S3). In BB medium, it seems that the $\mathrm{pH}$ does not influences the aggregates size, unlike the time, which played a notable role on this parameter, as the aggregates seem to increase manifold throughout the days. The same phenomenon happened in SRW, but in this case the decrease in $\mathrm{pH}$ also lead to an increment on the aggregates sizes.

These characterization studies showed that BT NP presents a higher reactivity than BT MP, and that SRW is a more instable medium and then contributes to this behavior, accordingly to the zeta potential and dissolution experiments results. Yet, the time the particles remain in suspensions lead to an increment in aggregate formation. Once again, these different behaviors can be expected to lead to different effects on the growth of $C$. vulgaris green algae.

\section{Toxicological assessment}

The toxicological assessment was conducted using not only the traditional BB culture medium but also the SRW, on the assumption that culture media may not be always representative of the actual behavior of particles into the environment. Figure 2 shows the growth of $C$. vulgaris as a function of time of exposure to BT particles. In spite of the relatively brief test duration, effects over several generations can be assessed because of the division rate the algae possess. As the system response is the reduction of growth in the exposed cells, one can infer that both BT MP and BT NP were toxic for $C$. vulgaris in BB and SRW at all concentrations tested $(p<0.05)$, although it seems that this effect increases with concentration. Yet, this effect was observed from the very first cell counting determination (24 h).

On the other hand, $\mathrm{Ba}^{2+}$ did not present significant reduction on the algae growth. From the literature, its toxicity is lower than most of the heavy metals (López-Roldán et al. 2013), and previous studies confirm that this metallic alkaline earth metal is toxic only at very high concentrations (Lamb et al. 2013; Monteiro et al. 2011; Kopittke et al. 2011), inclusive for C. vulgaris (den Doore de Jong and Roman 1965).

\section{C. vulgaris - BB medium}

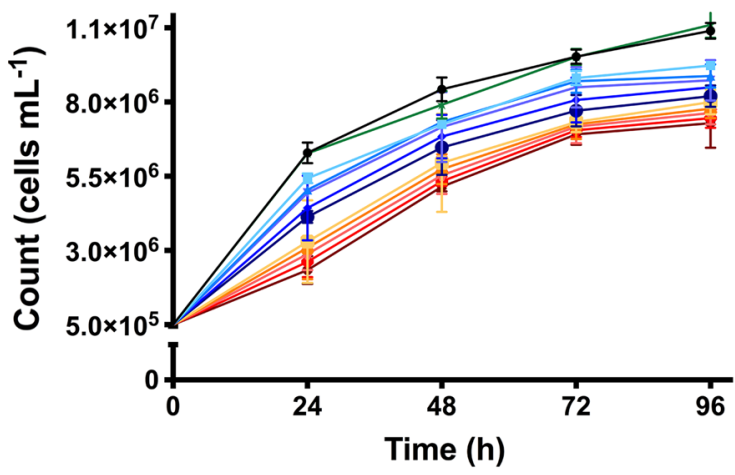

C. vulgaris - Seine River Water

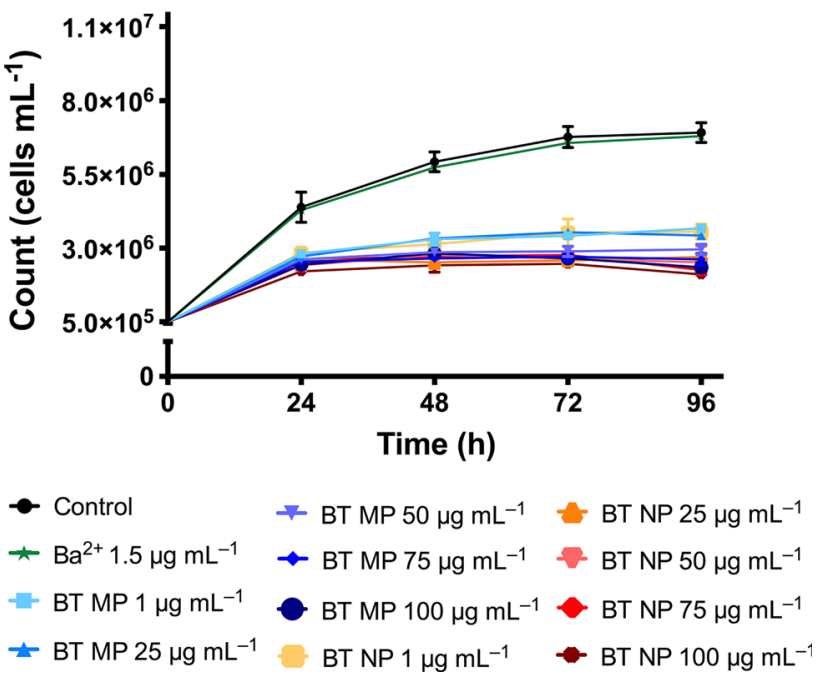

Fig. 2 Number of C. vulgaris cells as a function of concentration and time of exposure to barium titanate (BT) particles. Values represent mean \pm standard deviation $(n=3)$. All concentrations of BT MP and BT NP, but not the $\mathrm{Ba}^{2+}$ ion, led to significant reduction on the number of cells since the $24 \mathrm{~h}$ of test $(p \leq 0.05)$

Regarding the media used, the decrease in growth was much more pronounced in the SRW, which was expected from the characterization results. The lower cell numbers observed in SRW can be hypothesized to have occurred due to a theoretical paucity of nutrients (nitrate, phosphate, carbon sources such as glucose), which is often observed at the Seine river (Planchon et al. 2013), and so a worse physiological state of the algae in SRW can occur and account for the lower resistance. Yet, the possibility of a synergistic effect with a contaminant from the SRW cannot be discarded.

This trend was also observed when evaluating cell viability (Fig. 3), which was, in a general manner, lower in SRW than in BB. We observed that $C$. vulgaris exposed to BT in both media had a decreased ability to exclude dye, although in BB the lower concentrations of BT MP (1-50 $\mu \mathrm{g} \mathrm{mL}^{-1}$ ) did not seem to affect the membrane 

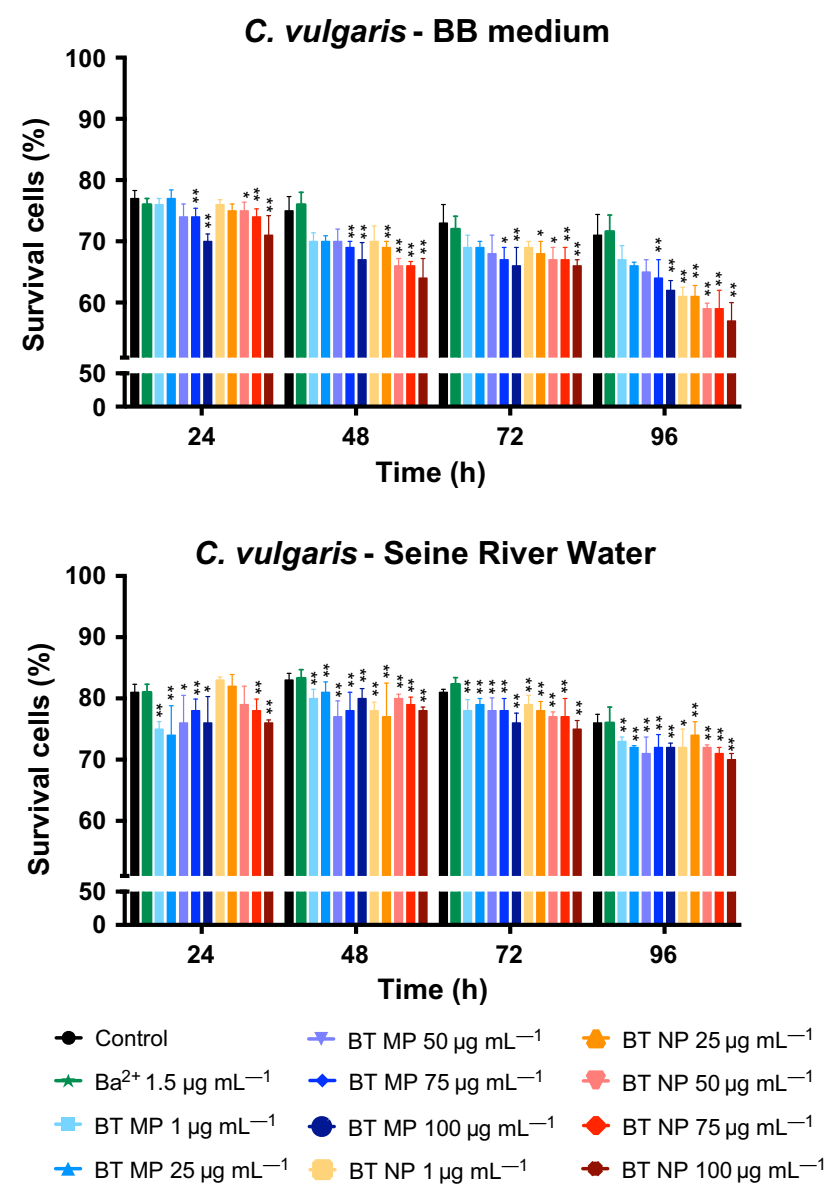

Fig. 3 C. vulgaris viability as a function of concentration and time of exposure to barium titanate particles. Values represent mean \pm standard deviation $(\mathrm{n}=3)$. Differences among groups are indicated by asterisk (marginally significant, $0.05<p \leq 0.1$ ) or double asterisk (significant, $p \leq 0.05$ )

integrity regardless the time of exposure, while BT NP affected this parameter at any concentration. The fact that the algae growth in SRW showed lower viability can be explained on the grounds that the culture media can influence the expression of cell membrane proteins (Haniu et al. 2013), which can account for the different responses for cell growth and viability observed in the two media.

The toxic effects of BT MP and BT NP on C. vulgaris growth and viability may have different origins, based on what is already known from the literature. The two main possible mechanisms are: (i) a direct contact of BT particles with the cell wall (Gogniat et al. 2006), linked to a theoretical penetration of the smallest particles (Planchon et al. 2013), which could explain the smaller growth for BT NP than for BT MP; and/or (ii) an indirect effect through the generation of reactive oxygen species (ROS) (Brayner et al. 2006; Chae et al. 2011). Thus, we performed different assays to assess which is the possible one involved in BT toxicity to $C$. vulgaris.
Assessment of the factors linked to the toxicity

Departing from the first theory, linked to the adsorption and penetration of BT by the cell membrane, SEM and TEM imaging were performed (Fig. 4). By SEM, one can see that there is no BT MP or BT NP particle adsorbed by the algae membranes, and by TEM one can hypothesize that there is no detectable particle inside the cells vesicles (although a coupled technique such as energy-dispersive $\mathrm{X}$-ray spectroscopy, EDS, would be necessary to confirm this). It is possible to observe the formation of large and compact particle aggregates within the algae culture, surrounding the cells, but with no apparent direct contact. Yet, the SEM images showed that exposed cells produced a gum-like material, which was not observed in the controls, which is consistent with the theory that the particles were not internalized. Previous studies have already detected this phenomenon, related to the cell ability of $C$. vulgaris to produce a sugar-residue composed, high-molecular-weight polymer known as exopolysaccharide (EPS) as a form of adaptive protection (Pereira et al. 2014). This EPS not only prevented the direct contact of the particles with the cell, but also formed particles aggregates surrounding the algae, what prevents the particle internalization (Pereira et al. 2014).

This non-internalization phenomenon found a basis in the zeta potential results. In Supplementary Fig. S5, one can see that the algae cells without materials being added to them are normally negatively charged. The particles are also naturally negatively charged, and this is coherent with an electrostatic repulsion the algae would exert upon the particles, and vice versa, which hampers absorption. This would be helped by the production and release of EPS into the media.

Another indicator of the importance the BT aggregate sizes played in the $C$. vulgaris toxicity is the fact that the results for hydrodynamic size (Supplementary Fig. S5) in both media were quite similar, but there was an increase in the values over time that followed the increase in the inhibition of growth and in cell viability. This increase may be due to an increase in the production and release of EPS, which would gradually imprison a higher amount of particles.

The possible mechanism of indirect toxicity via oxidative stress was assessed. The inhibition rate of the SOD activity (Fig. 5) did not greatly differ from the controls in BB medium. After $48 \mathrm{~h}$, there was a slight increase in activity, but none of the concentrations tested differed statistically from the respective control. The treatments in SRW, in turn, presented a higher inhibition since the first day of exposure, for the higher concentrations of BT NP, and for the higher concentration of BT MP and all concentrations of BT NP after $72 \mathrm{~h}$. SOD activity is crucial 

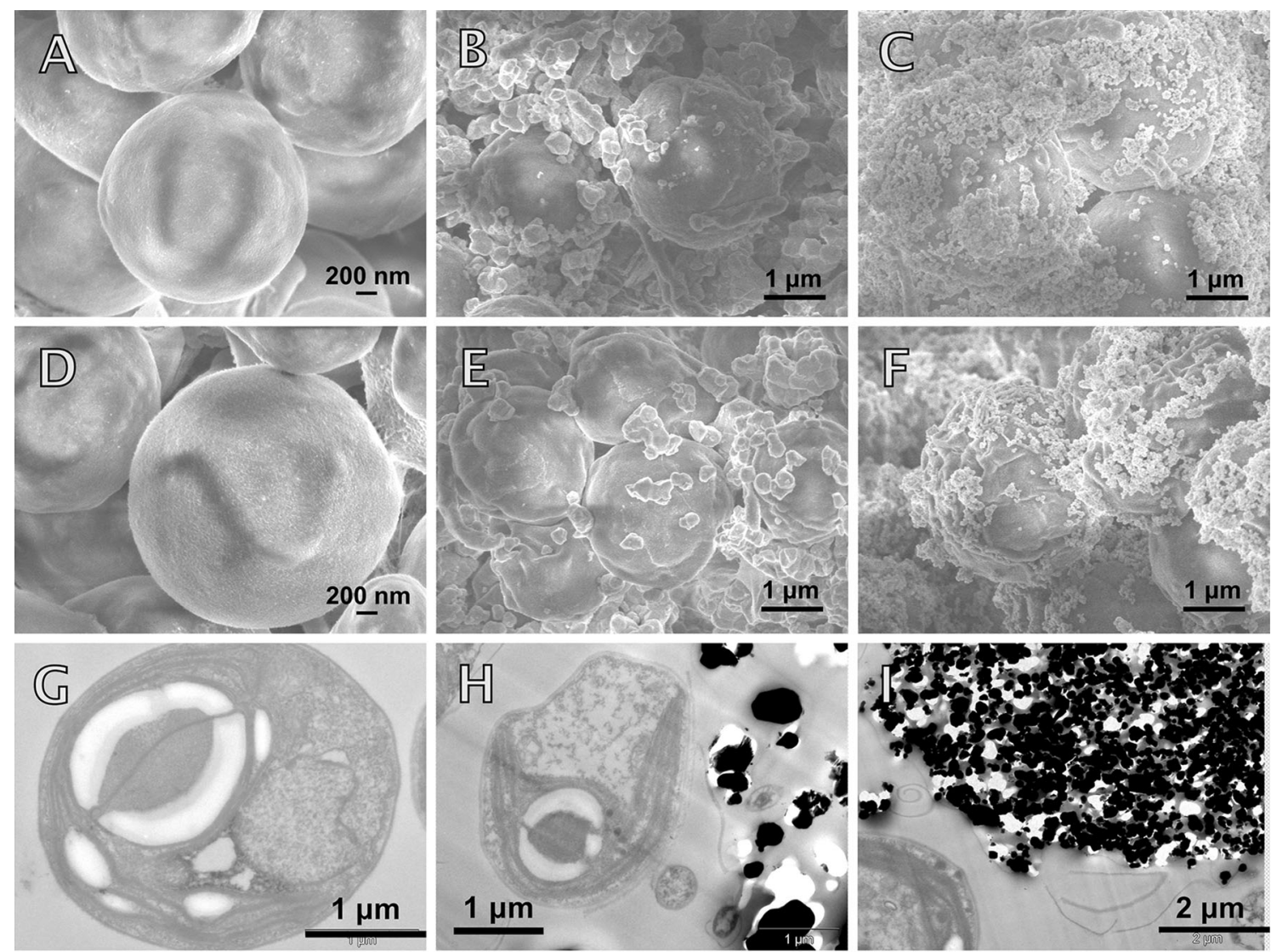
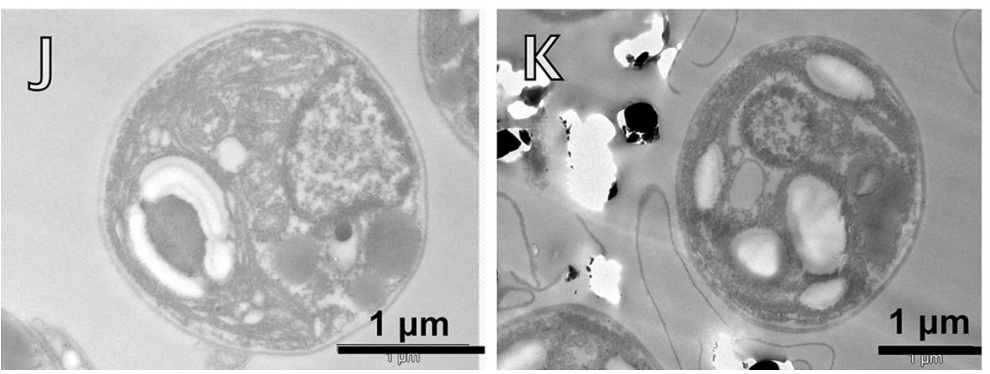

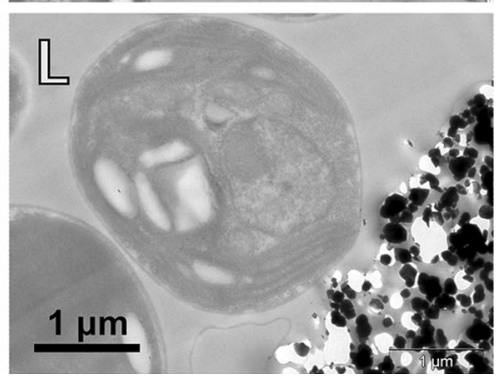

Fig. 4 SEM micrographs of C. vulgaris in BB medium [a control, b exposed to BT MP, c exposed to BT NP] and in SRW [d control, e exposed to BT MP, $\mathbf{f}$ exposed to BT NP]. TEM micrographs of $C$.

for the cells, since it protects them from the action of ROS. Then, a higher SOD activity can be a reflection of a higher exposure/production of ROS, which in turn, is associated with the activation of cell apoptosis via the mitochondria (Cheng et al. 2011) - this supports the theory that the particles-induced ROS generation in cells can cause the cell death. To that extend, the higher mortality observed in SRW can be linked to the increase in SOD activity-i.e. the toxicity may have occurred via exposure to ROS generated by BT. This is an effect consistent with data from the literature concerning other materials that influenced cell viability (Di Giorgio et al. 2011; Pereira et al. 2014). vulgaris thin sections in BB medium [ $\mathbf{g}$ control, $\mathbf{h}$ exposed to BT MP, $\mathbf{i}$ exposed to BT NP] and in SRW [ $\mathbf{j}$ control, $\mathbf{k}$ exposed to BT MP, I exposed to BT NP]

The SOD enzyme catalyzes the superoxide dismutation $\left(\mathrm{O}_{2}{ }^{-}\right)$into oxygen and hydrogen peroxide, being essential to the antioxidative balance of cells. The increased activity of SOD in cells grown in SRW after contact with BT is an indicative of a theoretical survival mechanism for $C$. vulgaris to reduce cytotoxic effects (Pereira et al. 2014. Nevertheless, one could see that the intracellular antioxidant system was not able to prevent the cell death (see Viability results). Within this context, one can consider the generation of ROS as a capital parameter that contributed to the toxicity of BT, notably in SRW.

As the particles led to the formation of large aggregates of particles, surrounding the algae, one can expect that this 


\section{C. vulgaris - BB medium}

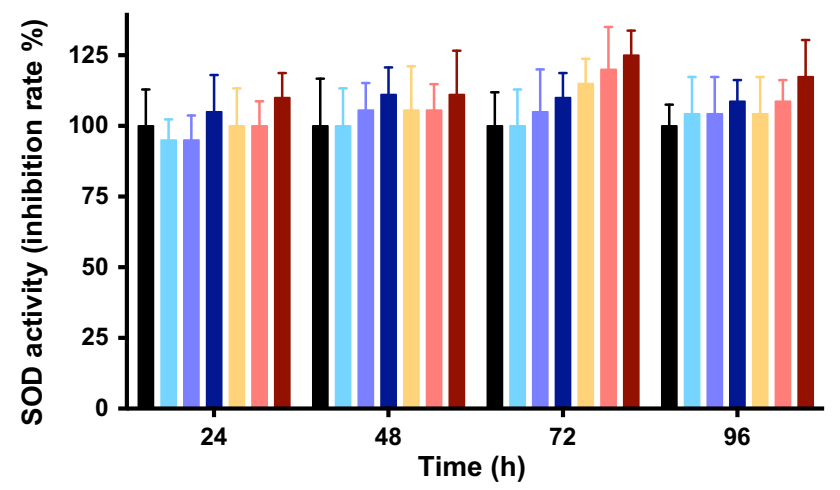

C. vulgaris - Seine River Water

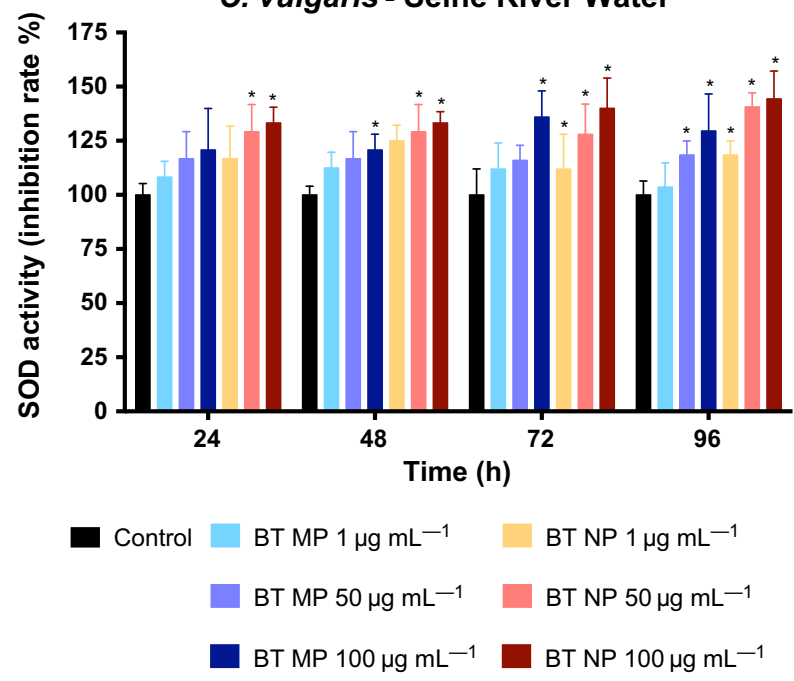

Fig. 5 Superoxide dismutase (SOD) activity of C. vulgaris as a function of concentration and time of exposure to barium titanate particles. Values represent mean \pm standard deviation $(\mathrm{n}=3)$. The asterisk indicate significant differences among groups $(p \leq 0.05)$

has caused a decrease in the availability of necessary nutrients for the algae growth, because their transport by the cell membrane was disturbed-and even the light availability could be threatened by these large metallic aggregates-which in some degree could have subjected the cells to stress, causing the increase in ROS production (Rogers et al. 2010; Xin et al. 2010). The accumulation of hydrogen peroxide irreversibly inactivates SOD, disturbing the synthesis of this enzyme by damaging the mitochondrial function (Zupan et al. 1996); yet, the impairment in the natural antioxidant defense system undermines the ROS detoxification, and this, for its turn, magnify the death of cells subjected to oxidative challenge (Chirino et al. 2010).

In addition, the increased ROS production can cause inhibition in the algae photosynthesis (Rodea-Palomares et al. 2012) (Fig. 6). Indeed, the photosynthetic activity was more reduced in SRW then in BB medium, which statistically decreased only after $96 \mathrm{~h}$, for the BT NP.

\section{C. vulgaris - BB medium}

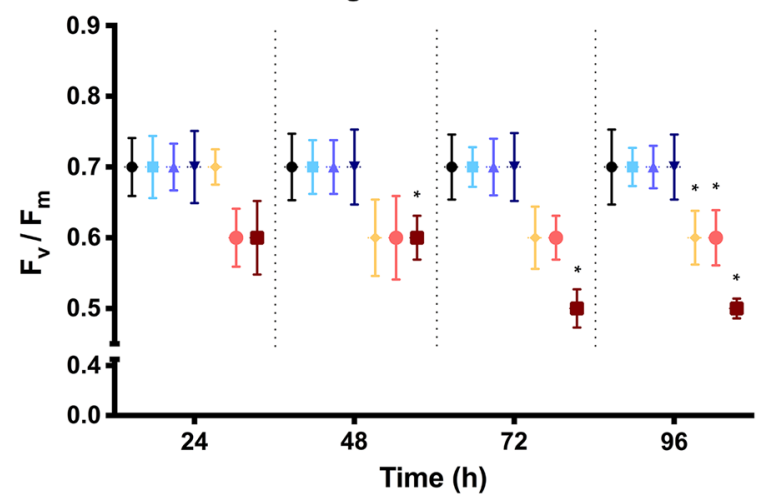

C. vulgaris - Seine River Water

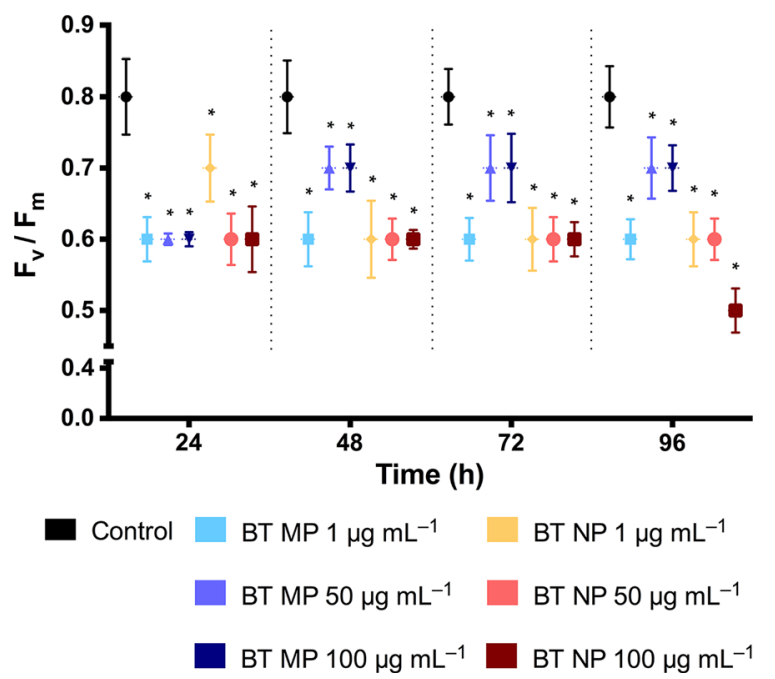

Fig. 6 Photosynthetic activity of $C$. vulgaris as a function of concentration and time of exposure to barium titanate particles. Values represent mean \pm standard deviation $(\mathrm{n}=3)$. The asterisk indicate significant differences among groups $(p \leq 0.05)$

However, in SRW this activity was reduced from the very first day until the last one, for all materials and concentrations, which is in accordance with the higher mortality found in this medium and the higher SOD activity detected. The actual impact of BT on cell oxidative stress is little known, as there is a lack of literature on this topic, but some studies have demonstrated the decrease in the activity after exposure to other nanoparticules such as $\mathrm{ZnO}$ (Brayner et al. 2010) and carbon nanotubes (Pereira et al. 2014). As they are related factors, the photosynthetic activity decrease may have the same sources as the SOD inhibition, such as shading factors caused by the formation of aggregates surrounding the cells. It is also plausible that the exposure to high concentrations of BT affected the photosynthesis in the algae through modifications in the PSII photochemical, caused by a defect in the quantum yield of PSII itself, such as non-photochemical quenching (Rodea-Palomares et al. 2012; Gao et al. 2013). 

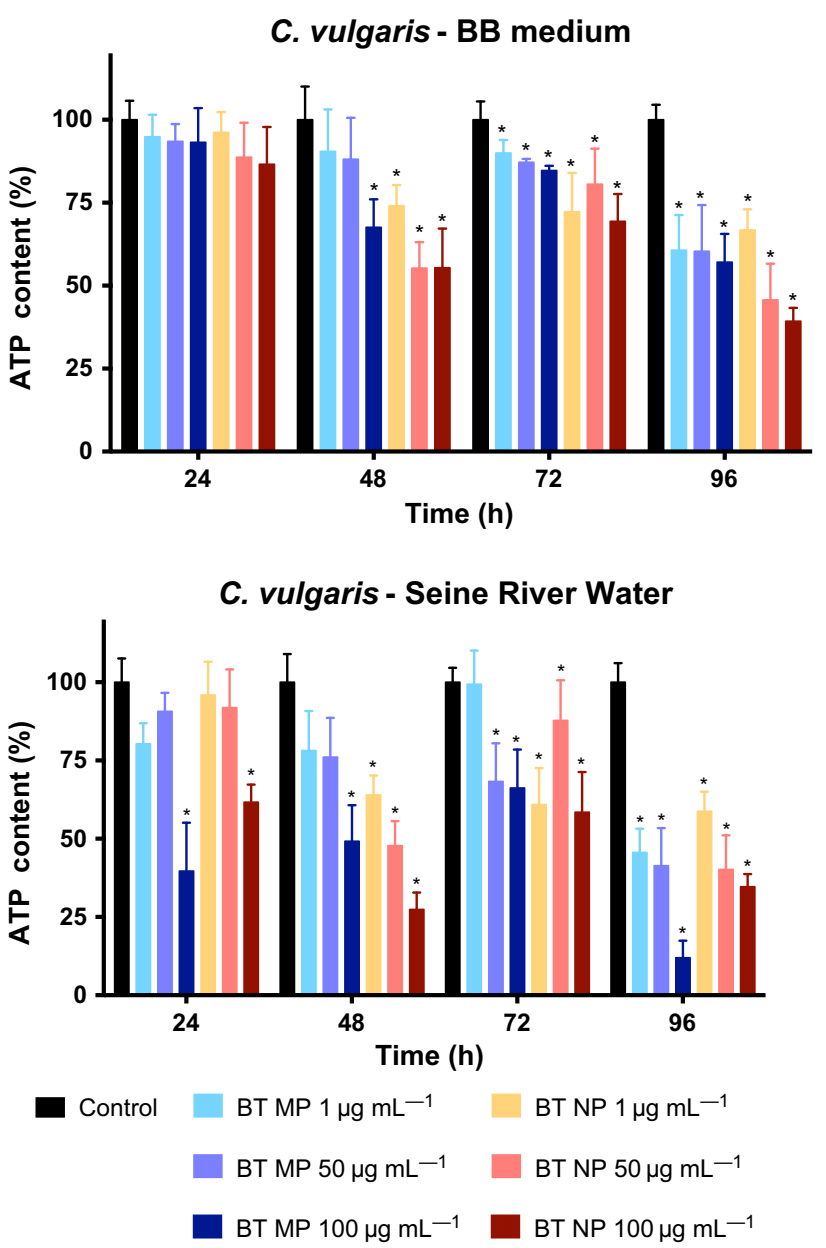

Fig. 7 Adenosine-5-triphosphate (ATP) content of C. vulgaris as a function of concentration and time of exposure to barium titanate particles. Values represent mean \pm standard deviation $(\mathrm{n}=3)$. The asterisk indicate significant differences among groups $(p \leq 0.05)$

Another direct parameter related to the mitochondrial activity of the cells is the intracellular ATP content (Fig. 7). The mitochondria are directly related to the cell viability, since they are responsible not only for the ATP production, but also for the ROS production and for the release of proteins that control the apoptosis (Pereira et al. 2014). The decline in ATP content may reflect a decrease in the mitochondrial activity, and so the BT particles lead to disturbances on the energetic metabolism of the algae. This effect is more noticeable after $48 \mathrm{~h}$ of exposure, for all concentrations of BT NP and for the higher concentration of BT MP, in both media.

\section{Conclusions}

Given the exposed, the main conclusions one can have from the present study are: (i) BT have an statistically significant toxic effect on $C$. vulgaris growth since the lower concentration tested (1 ppm), what seems to be mediated by a induced oxidative stress; (ii) the BT behavior in synthetic and natural culture media were different, being the toxic effects in $C$. vulgaris more pronounced when growth in SRW; and (iii) size does not seem to be an issue in BT particles toxicity since micro- and nano-particles produced significant effects on algae growthalthough the growth inhibition was more pronounced with the nanomaterial.

Acknowledgments H. Polonini thanks CAPES (04/CII-2008-Project 7, Network Brazil Nanobiotec) and Programa Ciência sem Fronteiras/ CNPq (245781/2012-9) for the scholarships granted. All authors thank Institut Jacques Monod (Université Paris Diderot, Paris, France); FAPEMIG; prof. Dr. Marcone A. L. de Oliveira (experimental design); Sophie Nowak (XRD analysis); Jean-Yves Piquemal (BET analysis); and Philippe Decorse (XPS analysis).

Conflict of interest The authors declare that they have no conflict of interest.

\section{References}

Ball JP, Mound BA, Nino JC, Allen JB (2014) Biocompatible evaluation of barium titanate foamed ceramic structures for orthopedic applications. J Biomed Mat Res Part A 102:2089-2095

Brayner R, Ferrari-Iliou R, Brivois N, Djediat S, Benedetti MF, Fiévet F (2006) Toxicological impact studies based on escherichia coli bacteria in ultrafine $\mathrm{ZnO}$ nanoparticles colloidal medium. Nanoletters 6:866-870

Brayner R, Dahoumane SA, Yéprémian C, Djediat C, Meyer M, Couté A, Fiévet F (2010) ZnO nanoparticles: synthesis, characterization, and ecotoxicological studies. Langmuir 26:6522-6528

Chae SR, Watanabe Y, Wiesner MR (2011) Comparative photochemical reactivity of spherical and tubular fullerene nanoparticles in water under ultraviolet (UV) irradiation. Water Res 45:308-314

Cheng WW, Lin ZQ, Wei BF, Zeng Q, Han B, Wei CX, Fan XJ, Hu CL, Liu LH, Huang JH, Yang X, Xi ZG (2011) Single-walled carbon nanotube induction of rat aortic endothelial cell apoptosis: reactive oxygen species are involved in the mitochondrial pathway. Int J Biochem Cell Biol 43:564-572

Chirino YI, Sánchez-Pérez Y, Osornio-Vargas AR, Morales-Bárcenas R, Gutiérrez-Ruíz MC, Segura-García Y, Rosas I, PedrazaChaverri J, García-Cuellar CM (2010) PM(10) impairs the antioxidant defense system and exacerbates oxidative stress driven cell death. Toxicol Lett 193:209-216

Choi HS, Liu W, Misra P, Tanaka E, Zimmer JP, Ipe BI, Bawendi MG, Fragioni JV (2007) Renal clearance of quantum dots. Nat Biotechnol 25:1165-1170

Ciofani G, Danti S, Moscato S, Albertazzi L, D’Alessandro D, Dinucci D, Chiellini F, Petrini M, Menciassi A (2010a) Preparation of stable dispersion of barium titanate nanoparticles: potential applications in biomedicine. Colloids Surf B 76:535-543

Ciofani G, Danti S, D’Alessandro D, Moscato S, Petrini M, Menciassi A (2010b) Barium titanate nanoparticles: highly cytocompatible dispersions in glycol-chitosan and doxorubicin complexes for cancer therapy. Nanoscale Res Lett 5:1093-1101 
Cullen LG, Tilston EL, Mitchell GR, Collins CD, Shaw LJ (2011) Assessing the impact of nano- and micro-scale zerovalent iron particles on soil microbial activities: particle reactivity interferes with assay conditions and interpretation of genuine microbial effects. Chemosphere 82:1675-1682

den Doore de Jong JE, Roman WB (1965) Tolerance of Chlorella vulgaris for metallic and non-metallic ions. Antonie Van Leeuwenhoek 31:301-313

Di Giorgio ML, Di Bucchianico S, Ragnelli AM, Aimola P, Santucci S, Poma A (2011) Effects of single and multi walled carbon nanotubes on macrophages: cyto and genotoxicity and electron microscopy. Mutat Res 722:20-31

Gao J, Xu G, Qian H, Liu P, Zhao P, Hu Y (2013) Effects of nano$\mathrm{TiO}_{2}$ on photosynthetic characteristics of Ulmus elongata seedlings. Environ Pollut 176:63-70

Gogniat G, Thyssen M, Denis M, Pulgarin C, Dukan S (2006) The bactericidal effect of $\mathrm{TiO}_{2}$ photocatalysis involves adsorption onto catalyst and the loss of membrane integrity. FEMS Microbiol Lett 258:18-24

Handy RD, Kammer FVD, Lead JR, Hassellöv M, Owen R, Crane M (2008) The ecotoxicity and chemistry of manufactured nanoparticles. Ecotoxicology 17:287-314

Haniu H, Saito N, Matsuda Y, Tsukahara T, Maruyama K, Usui Y, Aoki K, Takanashi S, Kobayashi S, Nomura H, Okamoto M, Shimizu M, Kato H (2013) Culture medium type affects endocytosis of multiwalled carbon nanotubes in BEAS-2B cells and subsequent biological response. Toxicol In Vitro 27:1679-1785

Hoshino A, Fujioka K, Oku T, Suga M, Sasaki YF, Ohta T, Yasuhara M, Suzuki K, Yamamoto K (2004) Physicochemical properties and cellular toxicity of nanocrystal quantum dots depend on their surface modification. Nano Lett 4:2163-2169

Hsieh CL, Grange R, Pua Y, Psaltis D (2010) Bioconjugation of barium titanate nanocrystals with immunoglobulin $\mathrm{G}$ antibody for second harmonic radiation imaging probes. Biomaterials $31: 2272-2277$

Jiang J, Oberdörster G, Biswas P (2009) Characterization of size, surface charge, and agglomeration state of nanoparticle dispersions for toxicological studies. J Nanoparticle Res 11:77-89

Kopittke PM, Blamey F, McKenna BA, Wang P, Menzies NW (2011) Toxicity of metals to roots of cowpea in relation to their binding strength. Environ Toxicol Chem 30:1827-1833

Lamb DT, Matanitobua VP, Palanisami T, Megharaj M, Naidu R (2013) Bioavailability of barium to plants and invertebrates in soils contaminated by barite. Environ Sci Technol 47:4670-4676

Lee BI (1998) Electrokinetic behavior of barium titanate powders in water. J Kor Phys Soc 32:S1152-S1155

López MCB, Fourlaris G, Rand B, Riley FL (1999) Characterization of barium titanate powders: barium carbonate identification. J Am Ceram Soc 7:1777-1786

López-Roldán R, Jubany I, Marti V, González S, Cortina JL (2013) Ecological screening indicators of stress and risk for the Llobregat river water. J Haz Mat 263:239-247
Monteiro FA, Nogueirol RC, Melo LCA, Artur AG, da Rocha F (2011) Effect of barium on growth and macronutrient nutrition in Tanzania guineagrass grown in nutrient solution. Comm Soil Sci Plant Anal 42:1510-1521

Montgomery DC (2012) Design and analysis of experiments, 8th edn. Wiley, New York

Nowack B (2009) The behavior and effects of nanoparticles in the environment. Environ Poll 157:1063-1064

Pang C, Selck H, Misra SK, Berhanu D, Dybowska A, Valsami-Jones E, Forbes VE (2012) Effects of sediment-associated copper to the deposit-feeding snail, Potamopyrgus antipodarum: a comparison of $\mathrm{Cu}$ added in aqueous form or as nano- and micro- $\mathrm{CuO}$ particles. Aquat Toxicol 106-107:114-122

Pereira MM, Mouton L, Yéprémian C, Couté A, Lo J, Marconcini JM, Ladeira LO, Raposo NRB, Brandão HM, Brayner R (2014) Ecotoxicological effects of carbon nanotubes and cellulose nanofibers in Chlorella vulgaris. J Nanobiotechnol 12:15

Planchon M, Ferrari R, Guyot F, Gélabert A, Menguy N, Chanéac C, Thill A, Benedetti MF, Spalla O (2013) Interaction between Escherichia coli and $\mathrm{TiO}_{2}$ nanoparticles in natural and artificial waters. Colloids Surf B 102:158-164

Polonini HC, de Oliveira MAL, Ferreira AO, Raposo NRB, Grossi LN, Brandão MAF (2011) Optimization of a new dissolution test for oxcarbazepine capsules using a mixed-level factorial design. J Braz Chem Soc 22:1263-1270

Rodea-Palomares I, Gonzalo S, Santiago-Morales J, Leganés F, García-Calvo E, Rosal R, Fernández-Piñas F (2012) An insight into the mechanisms of nanoceria toxicity in aquatic photosynthetic organisms. Aquat Toxicol 15:133-143

Rogers NJ, Franklin NM, Apte SC, Batley GE, Angel BM, Lead JR, Baalousha M (2010) Physico-chemical behaviour and algal toxicity of nanoparticulate $\mathrm{CeO}_{2}$ in freshwater. Environ Chem 7:50-60

Sivry Y, Gelabert A, Cordier L, Ferrari R, Lazar H, Juillot F, Menguy N, Benedetti MF (2014) Behavior and fate of industrial zinc oxide nanoparticles in a carbonate-rich river water. Chemosphere 95:519-526

Strober W (2001) Trypan blue exclusion test of cell viability. Curr Prot Immunol 21:A.3B.1-A.3B.2

Tiede K, Hassellov M, Breitbarth E, Chaudhry Q, Boxall ABA (2009) Considerations for environmental fate and ecotoxicity testing to support environmental risk assessments for engineered nanoparticles. J Chrom A 1216:503-509

Xin L, Hong-ying H, Ke G, Ying-xue S (2010) Effects of different nitrogen and phosphorus concentrations on the growth, nutrient uptake, and lipid accumulation of a freshwater microalga Scenedesmus sp. Biores Technol 101:5494-5500

Zupan G, Vitezić D, Mrsić J, Matesić D, Simonić A (1996) Effects of nimodipine, felodipine and amlodipine on electroconvulsive shock-induced amnesia in the rat. Eur J Pharmacol 310:103-106 